\title{
As Políticas de Avaliação da Educação Básica e o Trabalho Docente
}

\author{
Olgaíses Cabral Maués \\ Universidade Federal do Pará
}

\section{Resumo}

O trabalho tem como objetivo analisar as políticas de avaliação da educação básica estabelecidas a partir dos anos 1990, com aprofundamento nos anos 2000, bem como as repercussões no trabalho docente e na prática pedagógica, o que pode levar a uma uniformização das ações e realizar um estreitamento curricular. Procura-se demonstrar a influência que vem sendo exercida sobre os professores, que são impingidos a alcançar as metas estipuladas externamente, discutindo-se o sentido de responsabilização que esses profissionais vêm sofrendo.

Palavras-chave: Políticas de Avaliação. Responsabilização. Trabalho Docente. 


\section{The Evaluation Policies of Basic Education and the Teaching work}

The main goal of this study is to analise the evaliation policies of basic education established since 1990, focusing in the years 2000, and its consequences for the teaching work and for the pedagogical practice, that could be leading to the standardisation of the actions and the narrowing of the learning program. Here it will be presented the influencies that these policies have been exercised over the teachers, how they are foisted on to reach the goals that are set externally and the discussion about the sense of accountability that the teacher as professionals have been suffered.

Keywords: Evaluatio policies.Accountability. Teaching work.

\section{Las Políticas de Evaluación en la Educación Básica y el Trabajo de Enseñanza}

El estudio tiene como objetivo analizar las políticas de evaluación en la educación básica establecidas desde la década de 1990, profundizadas en los años 2000, y las repercusiones en el trabajo del docente y en la práctica pedagógica, lo que puede estar llevando a una estandarización de las acciones y el estrechamiento curricular. Se busca demostrar la influencia que se ejerce sobre los maestros incidido a alcanzar objetivos fijados externamente, cuestionándose el sentido de responsabilidad que estos profesionales han sufrido.

Palabras clave: Políticas de Evaluación. Responsabilización. Trabajo de Enseñanza. 


\section{Introdução}

Os anos 1990 trouxeram reformas estruturais em países da América Latina, em fase diferenciadas de desenvolvimento econômico e social. A motivação para essas reformas foram as imposições dos credores externos que exigiam um Estado "enxuto", que cortasse os excessos e, sobretudo, que se desburocratizasse. Para tal, era necessário reformar o Estado fazendo assumir medidas gerencialistas, próximas àquelas praticadas pelo mercado, na busca de eficiência e eficácia.

O Estado brasileiro se reestruturou e, segundo os reformadores, devia implementar uma gestão responsável pelo alcance dos resultados, premiando os servidores pelo bom desempenho e punindo aqueles que não alcançassem as metas ; devia realizar serviços através de agências executivas e reguladoras, transferindo "a oferta dos serviços sociais e científicos para organizações sociais, ou seja, para provedores públicos não estatais que recebem recursos do Estado e são controlados através de contrato de gestão". (Bresser-Pereira, 2010, p. 113).

Nesse modelo, implanta-se o Estado Regulador (Afonso, 2005) e Avaliador (Broadfoot, 2000), isto é, aquele ente que determina os objetivos e metas e que vai cobrar os resultados a serem alcançados, exercendo, assim, um controle sobre os sistemas sociais, econômicos e políticos.

As influências do modelo do "novo" Estado tiveram fortes repercussões na educação, na medida em que esse fenômeno social passou a ser considerado como um dos principais indutores do crescimento econômico do país.

É na lógica do Estado Regulador e Avaliador que se definirão as políticas e vão se estabelecer as novas regulações educacionais, isto é, as orientações das condutas dos atores e a definição das 'regras do jogo' em um sistema social.

Neste texto, parte-se da tese de que as políticas de avaliação estabelecidas pelo governo brasileiro, a partir dos anos 1990, com aprofundamento nos anos 2000, têm repercurtido no trabalho docente e na prática pedagógica, uniformizando as ações e realizando um estreitamento curricular, com fins de atender os índices estipulados pelo governo e atingir a performance considerada positiva para a educação básica.

Para demonstrar essa tese, em um primeiro momento, abordaremos o papel que o Estado passou a desempenhar a partir da reforma vivida nos anos 1990, que teve como objetivo transformá-lo em um ente que pudesse dar conta das demandas postas pela globalização da economia. Em seguida, analisaremos as repercussões dessa reforma no sistema educacional, a partir das determinações de um Estado regulador e avaliador. Também examinaremos o papel dos organismos internacionais para a difusão da avaliação educacional enquanto uma política de Estado, que deve estar voltada para a prestação de contas, a partir de objetivos pré-definidos, transformando a avaliação em uma forma de controle do conteúdo 
a ser ensinado nas escolas, sendo utilizada pelo Estado com o discurso da qualidade da educação. Em seguida, analisaremos a "obrigação dos resultados", ou o accountability como uma panaceia que vem assolando os sistemas de ensino. A questão da utilização da avaliação como forma de aproximar os sistemas escolares das demandas do mercado será analisada procurando-se mostrar que a opinião dos empresários da educação vem tendo um peso significativo na definição das políticas educacionais. Finalmente, será examinada a política de avaliação para a educação básica, procurando-se demonstrar a influência que vem sendo exercida sobre os professores, que são impingidos a alcançarem as metas estipuladas por pessoas de fora da escola, discutindo-se o sentido de responsabilização que esses profissionais vêm sofrendo para que alcancem os índices estabelecidos.

\section{O Estado reformado: a regulação e a avaliação}

O Estado brasileiro viveu nos anos de 1990 uma reforma que alterou o paradigma existente no que se refere ao papel que esse ente deve desempenhar. A crise do capital que eclodiu nos anos 1970 - e se prolongou para além daquela década - foi uma das razões para que os governantes, em uma onda mundial, vissem a premência e necessidade de reformar o Estado.

Para implementar a concepção de um Estado "enxuto"e "ágil", algumas medidas precisariam ser tomadas. Para Bresser-Pereira (1997), dentre os problemas que envolvem essa reforma destaca-se a redefinição do papel regulador do Estado, o que o autor considera um problema econômico-político que merecia um tratamento especial. Assim, novas regulações foram definidas, tendo o governo criado agências reguladoras que passaram a ter o papel de estabelecer os princípios, os objetivos e as metas de cada área política, econômica e social. As novas regulações incidiram, sobretudo, nas áreas de gestão, financiamento e avaliação, criando regras, normas e instrumentos de controle.

Para Maroy e Dupriez (2000), a regulação, no sentido mais largo, constitui-se em um processo de produção de regras que servirão como orientação das condutas de diferentes atores. Essa compreensão é de que a regulação representa um conjunto de mecanismos que permitirão o controle, por meio do qual um sistema busca manter o equilíbrio ou orientar as ações dos sujeitos (Lessard, 2006). Para esse último autor, a regulação depende de inúmeros fatores, mas não se deve perder o foco de que é a realização de um ajuste nos sistemas do estabelecimento de regras de acordo com o Estado e com o mercado, buscando atender aos interesses de ambos, já que possuem finalidades distintas.

Para os reformadores, orientados pelos organismos internacionais, era preciso transformar o estado burocrático em um estado pós-burocrático, gerencialista. Para 
Maroy (2006, p. 53), esse modelo pode ser considerado como o Estado avaliador, também chamado de "governança pelos resultados" e tem como princípio que os objetivos e programas sejam definidos de forma centralizada.

O mesmo autor ( 2008) explicita o que ele considera como um Estado pósburocrático, afirmando que esse não é fundado sobre a legitimidade da razão, da racionalidade, elementos típicos do Estado burocrático, mas é fundado sobre os resultados, a busca da eficácia, informando, ainda, que a racionalidade é valorizada, mas é, na realidade, transformada em racionalidade instrumental.

O Estado Avaliador passa a funcionar a partir das regulações, estabelecendo metas e verificando os resultados alcançados, que servirão de parâmetros para a definição de políticas, ou para alinhar aquelas existentes, para distribuir os recursos financeiros e para exercer o controle sobre as instituições.

\section{O Estado regulador e avaliador e a educação}

$\mathrm{Na}$ medida em que o Estado assumiu o papel de avaliador, em função das características gerencialistas que adquiriu na reforma sofrida, o governo central passou a ter a função de exercer um forte controle nas escolas, por meio de um sistema de avaliação que busca "amarrar" os conteúdos ensinados, estabelecendo metas que, caso sejam atingidas, permitirão, na concepção dos reformadores, o alcance de melhor qualidade do ensino.

Nessa lógica, a avaliação passa a exercer um poder superior sobre o sistema escolar, sendo capaz de definir o peso e o significado do que deva ser ensinado, influenciando o currículo e a dinâmica da escola.

Freitas (2007) sintetiza muito bem o papel do estado avaliador e regulador que define as regras e orientações (regulações), a fim de responder às questões que vão indicar os conhecimentos que as crianças necessitam aprender; as metodologias que podem ajudar no processo de aprendizagem; e, em função disso, como os professores que trabalharão com essas crianças e com esses conhecimentos devem ser formados e em quais instituições (universidade, faculdades, institutos), tanto na modalidade presencial como também a distância. Esse Estado também define os instrumentos avaliativos que verificarão os resultados dessas normas estabelecidas.

Para alguns autores, esse controle do conteúdo do currículo que a avaliação passou a exercer, transformou-a em um instrumento de accountability (Broadfoot, 2000), de prestação de contas. É utilizado por aqueles que têm o poder de definir o que é esperado das escolas no tocante aos ensinamentos ministrados. Para essa autora, pode-se considerar accountability como um processo que apresenta duas etapas. 
Em um primeiro momento, trata-se da comparação do sistema educacional em relação aos objetivos previamente determinados. A segunda etapa apresenta uma resposta às instituições educacionais a propósito de possíveis distanciamentos entre os objetivos estipulados e os resultados, indicando, por meio de mecanismos de controle, formas de reparar esses "desvios". Assim, pode-se dizer, segundo Broadfoot (2000), que o accountability tem como finalidade o controle exercido por aqueles que podem determinar os objetivos que a educação deve alcançar, a partir de interesses de grupos, de visão de mundo, de escolhas políticas.

Essa política de prestação de contas leva a outro aspecto do Estado Regulador e Avaliador: a responsabilização. No caso da educação, acaba impingindo às escolas e, sobretudo, aos professores a "culpa" por um resultado que seja considerado, nos padrões estabelecidos, ruim.

\section{A avaliação e os organismos internacionais}

Sabe-se que a avaliação interessa não apenas aos governos nacionais, mas também aos organismos internacionais que procuram valorizá-la, buscando demonstrar a importância que tem enquanto elemento de subsídio para a definição das políticas educacionais. Clarke (2012, p.1), em um documento chancelado pelo Banco Mundial (BM), é categórica quando afirma que "um sistema de avaliação é um grupo de políticas, estruturas, práticas e instrumentos para gerar e utilizar informações sobre a aprendizagem e aproveitamento do estudante". A autora deixa clara a importância de desenvolver sistemas sólidos que permitam não apenas verificar o avanço dos alunos, mas também que apontem as possíveis variáveis intervenientes nesse processo, assegurando, dessa forma, a possibilidade de resolver a questão.

A preocupação de Clarke (2012, p.2), referendado pelo BM, tem conotações econômicas, pois indica que "um desvio padrão nas pontuações de avaliações internacionais dos níveis de aproveitamento de leitura e matemática tem sido vinculado a um aumento de $2 \%$ em taxas de crescimento anual do PIB per capita" Quando o Banco Mundial (2010) faz uma análise das políticas públicas brasileiras e indica que o país vem "atingindo uma educação de nível mundial", a avaliação é apontada como um dos elementos que tem contribuído para esse avanço. Mais ainda, a criação do Sistema de Avaliação Educação Básica (Saeb) é apontada como uma das ferramentas que contribuiu efetivamente para a elevação do patamar educacional.

Levando em consideração a posição do Banco Mundial, pode-se entender melhor a preocupação que tem sido demonstrada pelos últimos governos brasileiros na adoção de políticas de avaliação. 
A Organização para Cooperação e Desenvolvimento Econômico (OCDE) já tem uma tradição concernente à avaliação, sendo o Programme for International Student Assessment (Pisa) - Programa Internacional de Avaliação de Alunos - a tradução desse interesse. O Pisa é um programa internacional de avaliação comparada e é aplicado para alunos na faixa de 15 anos, que seria a idade, em tese, do término da educação obrigatória. Tem como objetivo central a produção de indicadores sobre a qualidade da educação em cada país participante, com a finalidade de subsidiar as políticas educacionais.

O Programa de Promoção da Reforma Educativa na América Latina (Preal, 2011), fez um estudo sobre alguns países que alcançaram um alto resultado no Pisa em 2009 e apresenta algumas "lições" que podem ser adotadas para que se obtenham "altos desempenhos". Uma dessas lições é o estabelecimento de parâmetros ambiciosos, focalizados e coerentes que devam estar alinhados com o currículo e que devem ser verificados a partir de um sistema de avaliação bem estruturado.

Ravela et al (2008), em um documento do Programa de Promoción de la Reforma Educativa en América Latina y el Caribe (Preal), fazem uma defesa veemente da importância da avaliação em larga escala, externa, estandardizada como uma forma de definição do currículo formal, contribuindo para indicar o que os estudantes devem ter aprendido ao final de cada ciclo educativo.

A Unesco (2008), em um documento intitulado "Educação de Qualidade Para Todos: um assunto de direitos humanos", coloca a importância de políticas de avaliação focalizadas no rendimento dos estudantes e recomenda que é necessário fortalecer os sistemas de avaliação dos alunos, ampliando-os para além das áreas instrumentais básicas.

\section{A avaliação educacional enquanto obrigação dos resultados}

Demailly (2004) considera a obrigação dos resultados na educação enquanto uma nova regulação a partir da instituição do Estado Regulador e Avaliador. A defesa dessa regulação passa pelo discurso da prestação de contas dos recursos empregados e que devem ser transformados em rendimento escolar, eficiência, eficácia, qualidade e competência.

Ao examinar essa política de avaliação, centrada nos resultados, pensa-se em uma relação custo-benefício, ou custo-produtividade, numa clara ligação com as práticas do mercado nas empresas privadas e que se exprimem por meio de indicadores quantitativos, tornando-se os números a representação da excelência.

Claude Lessard (2004), analisando o caso de Quebec, indica-nos alguns aspectos aos quais a obrigação de resultados está vinculada. Começa o autor pela aprendizagem 
dos alunos, dizendo ser essa medida obtida por testes quantificados e comparados no tempo (períodos diferentes) e no espaço (regiões, cidades, escolas, países diferentes). São, assim, testes de larga escala aplicados a um grande número de pessoas, por vezes de caráter internacional, ou regional. Lembra o autor que esses testes são, em geral, de ordem cognitiva e os resultados desejados são pré-fixados, representando, por exemplo, um percentual de diplomados, uma taxa de aprovação.

autor citado (2004) informa que esse tipo de política é complementado pela divulgação dos resultados e pelas premiações ou punições que os estudantes, professores e escolas possam merecer e apresenta as críticas que essa obrigação de resultados, exigida pela política de avaliação, vem sendo alvo. A primeira crítica refere-se à visão reducionista que esse tipo de prestação de contas pode trazer, na medida em que a missão da escola não pode ser unicamente vinculada à aprovação de um grande número de pessoas que se submete a esse tipo de exame. Lessard lembra que o papel da escola é mais amplo e maior como, por exemplo, formar o cidadão esclarecido, crítico e engajado. Além disso, convém observar que algumas das competências intelectuais só se manifestam plenamente ao longo da vida e não necessariamente em provas e exames.

O mesmo autor (2004) apresenta um aspecto fundamental que deve ser observado pelos gerentes desse tipo de política: a obrigação de resultados não pode funcionar sem a obrigação de meios, de recursos (humanos, materiais, físicos ou econômicos).

Dessa maneira, é preciso realizar alguns questionamentos: quais as condições de infraestrutura das escolas nas quais esses alunos estudam? Qual o nível socioeconômico dos estudantes, em uma dada escola, que não obtiveram os índices estipulados? Quantas horas diárias os estudantes passam na escola? Quais as atividades complementares (dança, música, artes em geral, línguas estrangeiras, informática, esporte, ludicidade) oferecidas aos alunos? Outras questões podem, ainda, ser colocadas, como, por exemplo: qual o vínculo empregatício que os professores têm com a escola? Qual a carga horária dos professores? Esses docentes trabalham apenas em uma escola? Há um plano de carreira e salários para os professores? Como são recrutados? Existe, na escola, formação continuada para os professores?

Quando os resultados não são atingidos, mesmo sendo obrigatórios, outra política, a da responsabilização, é colocada em prática. Como consequência, os professores são os primeiros a serem imputados pelo dito fracasso dos alunos que não conseguiram atingir o índice determinado pelo governo central.

Brooke (2006, p.378) defende a posição de que há necessidade de se publicizar os resultados dos sistemas escolares, alegando que isso tem feito que surjam "políticas de accountability, ou seja, de responsabilização".

Para esse autor, a política de responsabilização contribui para tomada de decisão 
por parte das autoridades, na medida em que se tornam públicas as diferenças de nível de desempenho das escolas, permitindo que sejam estabelecidos critérios para aplicação de incentivos ou sanções de acordo com os resultados alcançados.

Freitas (2013) vem discutindo a questão da responsabilização e a analisa por outra ótica, diferente daquela de Brooke (2013), evidenciando que por trás dessa política existe o mercado, a quem os resultados das avaliações interessam muito, em função dos vários desdobramentos que ocorrem a partir da publicização das notas, dos conceitos dos diferentes testes padronizados e em larga escala que vêm, cada vez mais, sendo adotadas para todos os níveis de ensino e todas as etapas.

Os argumentos utilizados por Freitas (2012), relativos à teoria da responsabilização são muito claros. Analisemos alguns deles. Primeiramente, esse autor sustenta que a teoria da responsabilização tem um caráter meritocrático e gerencialista, isto é, o controle do sistema ocorre por meio de prêmio (bônus) ou punições (sanções). Em segundo lugar a avaliação expressa uma racionalidade técnica que se apresenta na forma de "standards" que são mensurados por meio de testes. Terceiro, a teoria tem 3 partes: os testes, a divulgação dos resultados e o sistema de recompensas/ punições.

A meritocracia está no centro dessa teoria e é vista como uma forma de justiça social, pois para "vencer" na vida o indivíduo não depende de herança cultural, nem da origem social, mas somente de seus próprios méritos.

Tenret (2008) alerta para a polissemia da palavra meritocracia, que pode designar tanto uma sociedade fundada sobre a recompensa pelo esforço realizado através do trabalho, quanto pode indicar uma sociedade fundada sobre o reconhecimento das capacidades. Parece-nos que as duas abordagens podem ser complementares na medida em que a recompensa via trabalho (esforço) ocorre como reconhecimento dessa capacidade (talento).

Outros autores veem a meritocracia escolar como uma espécie de justiça social, pois reconhece os talentos, os dons. Contudo, isso pode ser contestado, pois, na realidade, o sistema escolar, por exemplo, que premia os melhores, institui automaticamente um regime de competição, ou uma disputa darwiniana, na qual apenas os "melhores" vencem e os "fracos" ficam para trás.

É preciso tomar posição. Recorrendo a Freitas (2013), podemos dizer que não se está fazendo uma imagem negativa da avaliação. O que se está analisando e fazendo reflexões é de como, nas sociedades desenvolvidas, esse sistema passou a representar uma forma feroz de controle que é exercido em toda a sociedade e que na educação, em particular, transformou-se em uma política que tem priorizado as ações e os recursos para o fortalecimento da cultura do controle.

A responsabilização e a meritocracia podem levar à privatização. O raciocínio é que esse sistema de avaliação implementado em diferentes países tem como objetivo 
imputar à escola pública a incapacidade de poder desempenhar o papel de formação de pessoas. Dessa forma, por meio da meritocracia, que se manifesta pelos testes padronizados, externos e de grande escala, aponta-se com o dedo em riste para as escolas e para os professores. A partir daí, a saída parece inevitável, o setor privado pode dar conta melhor dessa função. O governo pode criar mecanismos que permitam ao setor privado assumir a educação, quer seja por meio de políticas de transferência de renda, como por exemplo, no caso brasileiro, o Programa Universidade para Todos (PROUNI), em que o governo fornece bolsa de estudos em instituições privadas ou por meio de parceria público-privada, na qual a gerência administrativa e pedagógica de uma escola pública passa a ser feita por uma empresa privada contratada e paga com recursos públicos.

O mercado passou a ter grande interesse por essa política de avaliação e vem atuando de maneira agressiva em diferentes sistemas educacionais dos estados e municípios, seja por meio de elaboração, correção dos testes que são aplicados, do mercado editorial, cujos livros procuram atender basicamente o que o sistema de avaliação vem apresentando, dos cursos de formação continuada para os professores em exercício, das consultorias às secretarias de educação com o objetivo de superação dos baixos índices que as escolas tenham alcançado.

É com esse quadro referencial que iremos analisar as Políticas de Avaliação da Educação Básica em curso no Brasil, procurando identificar e explicitar os impactos sobre os professores advindos desse conjunto de políticas públicas.

\section{O sistema de avaliação da educação básica}

No início dos anos de 1990, o governo federal começou, de forma efetiva, a discutir a necessidade da implantação de um sistema de avaliação. A preocupação com os resultados apresentados pelas escolas no que diz respeito à reprovação, à promoção, ao abandono de estudantes foi o motivo central para deslanchar esse processo.

Havia uma recomendação apresentada na Declaração Mundial de Educação para Todos, resultante da Conferência Mundial de Educação realizada em março de 1990 em Jontien, na Tailândia, que explicitava, no artigo $4^{\circ}$, a necessidade de garantir a aprendizagem aos alunos, precisando "[...] definir, nos programas educacionais, os níveis desejáveis de aquisição de conhecimentos e implementar sistemas de avaliação de desempenho" (UNESCO, 1990, p.3).

Nesse mesmo ano, o Brasil criou o Sistema de Avaliação da Educação Básica, tendo como objetivo avaliar e contribuir com a qualidade do ensino, visando universalizar o acesso à escola, "oferecendo subsídios concretos para a formulação, reformulação 
e o monitoramento das políticas públicas voltadas para a Educação Básica" (MEC/ INEP, 2014, p.1).

Quando do seu surgimento, esse sistema estava voltado apenas para realizar a avaliação por amostra de estudantes do $5^{\circ}$ e do $9^{\circ}$ ano do ensino fundamental, além do $3^{\circ}$ ano do ensino médio das escolas públicas e privadas. A partir de 2005, essa avaliação passou a ser chamada de Avaliação Nacional da Educação Básica (Aneb). O Saeb se ampliou e incluiu a Avaliação Nacional do Rendimento Escolar (Anresc), mais conhecida como Prova Brasil, que tem como finalidade realizar uma avaliação censitária que inclui os alunos apenas do ensino fundamental, $5^{\circ}$ e $9^{\circ}$ ano, envolvendo $\circ 3^{\circ}$ ano do ensino médio das escolas públicas das redes municipais, estaduais e federal. Tem o objetivo de avaliar a rede pública de ensino.

No ano de 2013 mais uma avaliação passou a fazer parte do Saeb, dessa feita foi a Avaliação Nacional de Alfabetização (ANA), também de caráter censitário, destinada aos alunos do $3^{\circ}$ ano do ensino fundamental das escolas públicas, tendo como escopo avaliar os níveis de alfabetização e letramento, alfabetização Matemática. Dessa forma o Sistema de Avaliação da Educação Básica está composto pela Aneb, Anresc e ANA.

O governo Federal instituiu, por meio do Decreto 6.094 de abril de 2007, o Plano de Metas Compromisso Todos pela Educação, que tem como finalidade, por meio de uma série de ações, a melhoria da qualidade da educação básica. Nesse mesmo Decreto, no artigo $3^{\circ}$, é criado o Índice de Desenvolvimento da Educação Básica (Ideb). Assim, foi instituído um indicador quantitativo que passou a orientar, de forma direta, todo o processo de ensino-aprendizagem dos estudantes brasileiros.

O Plano de Metas passou a representar um compromisso firmado pelos entes federados que aderiram a essa política, da qual a avaliação é a espinha dorsal que dá sustentação a todas as demais ações. A criação desse Índice fez com que a educação nacional orbitasse e orbite em torno dos componentes que vão compor esse indicador.

O Ideb apresenta o resultado obtido pelos estudantes nas provas de língua portuguesa e matemática e "é calculado a partir de dois componentes: taxa de rendimento escolar (aprovação) e médias de desempenho nos exames padronizados [...]" (MEC/INEP, 2014, p.1). Para obter as médias, são utilizados os resultados da ANEB e da Prova Brasil. Assim, o índice é constituído a partir dos dados do rendimento escolar, mais os dados do desempenho dos estudantes constantes do Censo Escolar, juntamente com o resultado da Aneb e da Prova Brasil.

Costa Almeida, et al (2013, p.1155) questionam o papel que o Ideb vem desempenhando como a "única fonte para a análise do trabalho desenvolvido pelas escolas". Na sequência, os autores comentam o que isso significa, principalmente, o fato de não ser considerado o nível sócio econômico dos estudantes. 
Essa questão foi discutida por Bourdieu e Passeron (1964) que, já na década de 1960, chamavam a atenção para a função da escola de legitimar e de perpetuar as desigualdades em função dos critérios de aprovação/reprovação empregados. Os privilégios concedidos a alguns que estariam vinculados ao mérito e a dons pessoais, a questão do capital cultural, da "herança" recebida da família, relacionada com a sua origem e posição social.

Os autores sofreram muitas críticas daqueles que viam nessa abordagem certo determinismo, não reconhecendo que a educação, no seu aspecto democrático, possa possibilitar a mobilidade social. Passados mais de 50 anos do aparecimento dessa análise, eis que novamente surge a questão do nível cultural como um dos elementos fundamentais a se considerar no emprego de índices que possam indicar o grau de sucesso ou fracasso escolar.

O Ideb passou a ser o grande balizador das políticas públicas educacionais, a ponto de constar no Plano Nacional de Educação (2014) uma Meta (a número 7) que apresenta um quadro indicativo da evolução do Ideb até o ano de 2021. A mesma meta também apresenta quadro similar referente ao Pisa, que em 2021 deverá ter alcançado 473 pontos. Esse fato revela o caráter e o significado desse tipo de avaliação, que passa, doravante, a ser uma política de Estado, adquirindo, com isso, a garantia de sua continuidade, independente de partidos políticos e governos que venham assumir a direção do país.

Para Krawczyk (2008, p.805) "fica clara a valorização exacerbada da interferência de instrumentos de avaliação para a mudança da realidade educacional brasileira". A avaliação passou a representar o carro chefe da educação brasileira, desempenhando o papel do principal elemento a ser considerado na tomada de decisões junto às escolas, quer seja envolvendo os professores, os gestores e até mesmo a comunidade.

\section{Os professores e as políticas de avaliação}

A educação brasileira está vivendo sob a égide das avaliações. As secretarias de educação, as unidades escolares, os professores, os diretores, os técnicos em educação, os supervisores escolares, todos e tudo vêm girando em função das avaliações. Há uma orientação explícita de que em ano de Prova Brasil, de ANA ou de Saeb (como é mais conhecida a Aneb) todas as atividades devem estar voltadas para essas avaliações externas, padronizadas e de larga escala.

Os professores são, do ponto de vista operacional, os mais atingidos por essa verdadeira obsessão pela avaliação. Como esse processo vem impactando no trabalho docente, na prática pedagógica desses professores? Os professores têm a dimensão desse processo avaliativo para formação dos alunos? 
Em uma pesquisa realizada em 2010, intitulada Trabalho Docente na Educação Básica no Brasil ${ }^{1}$, Maués (2012) informa que, no tocante aos dados referentes ao estado do Pará, destacam-se os seguintes: $55 \%$ dos professores trabalham em mais de uma unidade escolar; $30 \%$ têm um contrato temporário (substituto); $77 \%$ não têm um Plano de Carreira; apenas 13\% não levam, nunca, atividades para realizar em casa; $38 \%$ consideram insuportáveis os ruídos na escola e na sala de aula; $36 \%$ consideram ruim a ventilação em sala de aula; $85 \%$ gostariam de ter mais autonomia nas suas atividades docentes; $79 \%$ acreditam que o trabalho seria mais eficiente se houvesse melhores condições materiais; $35 \%$, em média, acham que não tem controle sobre a avaliação dos alunos, escolha do material didático e métodos de ensino; $90 \%$ acham que a atividade docente deve ser avaliada; $76 \%$ sentem-se responsáveis pelos resultados que os alunos obtém nas avaliações externas e 75\% sentem os impactos das políticas educacionais sobre suas tarefas; $49 \%$ acreditam que a situação socioeconômica precária das famílias dos estudantes interfere no processo de aprendizagem; $52 \%$ percebem que são o principal responsável pela cobrança do resultado de seu próprio trabalho. ${ }^{2}$

A apresentação desses dados tem como objetivo demonstrar, mesmo que parcialmente, as condições de trabalho que os professores da rede pública têm em geral $^{3}$, o que não é considerado nas avaliações que buscam os resultados, sem considerar o processo, que implica desde a formação dos professores até o salário recebido, passando pela forma de contratação, a existência de um plano de carreira, dentre outros fatores fundamentais para o processo ensino-aprendizagem.

Freitas (2012, p. 388-396) apresenta algumas consequências dessas avaliações que incidem sobre a escola e sobre o professor. $O$ estreitamento curricular é uma dessas consequências, talvez a mais perversa, na medida em que, a partir dessa política de obrigação de resultados, a carga horária para Língua Portuguesa e Matemática, disciplinas cujos conteúdos são objeto das avaliações externas, aumentou em detrimento das outras disciplinas. Ravitch (2011, p.117), falando dos Estados Unidos da América, informa que

Conforme os professores gastavam mais tempo preparando os estudantes para realizar testes padronizados, o currículo era enxugado, matérias como ciências, estudos sociais e artes eram deixadas de lado para arrumar tempo para a preparação para os testes.

Esse quadro não é diferente na realidade brasileira, que parece ter importado essa política de avaliação do modelo americano, mesmo as autoridades educacionais sendo alertadas para o fato de que tais ações não modificaram o quadro educacional

1 A pesquisa abrangeu 07 estados (Pará, Goiás, Rio Grande do Norte, Espírito Santo, Minas Gerais, Santa Catarina e Paraná) e foi coordenado em nível nacional pelas professoras Dalila Oliveira e Lívia Fraga, ambas da UFMG.

2 Os dados foram obtidos junto a 1350 sujeitos docentes, utilizando-se um survey e grupo focal.

3 Os dados apresentados se referem ao estado do Pará, mas os dados do Brasil estão todos na mesma média. 
norte-americano. Essa limitação em termos de matérias e de conteúdos a serem trabalhados nas escolas tem restringido os professores a tarefas repetitivas que se concentram nos simulados dos exames e no trabalho com os temas que vêm sendo demandados nessas avaliações. O trabalho pedagógico fica restrito, grosso modo, à preparação para os testes.

Outro impacto dessas avaliações sobre os professores, segundo Freitas (2012), é o acirramento da competição entre profissionais e escolas, que é manifestado pelos resultados que se apresentam, havendo mesmo, por parte dos próprios colegas de profissão, certo menosprezo em relação àqueles que não conseguiram alcançar as metas estipuladas pelas secretarias de educação. $A$ competição, elemento inerente ao liberalismo e que ficou mais acentuado com o neoliberalismo, acaba afastando os pares que veem sempre no outro um rival que poderá tirar de sua escola o "troféu" da melhor nota, por exemplo. A questão da formação continuada dos professores também acaba ficando restrita aos exames, poia a maioria das secretarias de educação implementa cursos obrigatórios que vão "preparar" os professores a "prepararem" os estudantes para fazer as provas, levando ao que Freitas (2012) chama de precarização da formação.

Contudo, um dos maiores impactos, segundo o mesmo autor, é a destruição moral do professor. Na pesquisa realizada no Pará, citada em parágrafos anteriores, os respondentes informaram que o grau de satisfação dos professores com a profissão é muito baixo. Também há um grande descontentamento com o próprio desempenho, que pode estar sendo inculcado por essa política de responsabilização, que faz uma ligação linear entre professor e resultado dos exames, mostrando-se absolutamente equivocado.

A segunda pesquisa da qual serão utilizados alguns dados trata-se da Tese de doutoramento de Mariza Felippe Assunção (2013). Os dados foram coletados com professores da educação básica da rede municipal de Belém. Os comentários dessas professoras durante a entrevista realizada pela pesquisadora trazem elementos importantes a serem considerados nesse processo de responsabilização, prestação de contas e punição. Um dos relatos feitos à entrevistadora dá conta de que professoras, cujas turmas não alcançaram a meta, foram trocadas para outras turmas, ou mudaram de Ciclo, indo para outro que seria, na cabeça dos gestores, menos "puxado". Outras professoras perderam carga horária, o que significa perda de salário. Há, na cabeça das professoras entrevistadas para essa pesquisa, de que o "objetivo é alcançar a média" e "ultrapassar essa média", é ter seu trabalho voltado só para isso (Assunção, 2013, 157-158). Esses professores parecem ter sido contaminados pela ideologia da avaliação, pois concordam, defendem essa política e, mais ainda, têm a "consciência de que é dever nosso, é uma obrigação nossa melhorar essa marca (o Ideb) porque é o nosso trabalho que está em jogo" (p.157). Essa professora que trabalha na rede municipal tem a convicção de que a nota do Ideb 
precisa melhorar e acha que a "escola tem que mudar para valer, já que estamos nos treinamentos, a direção quer sim uma mudança visível" (p.158). Há um processo de aceitação e acomodação desses professores, mesmo reconhecendo que os exames trouxeram mais trabalho, defendem que é preciso se envolver com isso, contagiarse e trabalhar duro para alcançar e até ultrapassar o que foi estipulado pelo governo federal em termos de resultados traduzidos por um índice que considera apenas parte da questão da qualidade da educação.

Os resultados das entrevistas realizadas para a Tese de doutoramento trouxeram surpresas à orientanda. O nível de aceitação apresentado pelos professores, a compreensão de que as avaliações externas vieram facilitar o trabalho pedagógico, pois, segundo essas entrevistadas, agora se tem manuais, livros, apostilhas que indicam exatamente o que se tem que ensinar (estreitamento curricular), não havendo perda de tempo com outros assuntos, devendo o trabalho está focado na Prova Brasil para melhora do Ideb.

A política de responsabilização parece ter sido plenamente introjetada nos professores que passaram a sentir no salário, no status e na própria valorização de sua profissão que existem consequências se os índices não forem atingidos. Ravitch (2011, p.177) também identificou isso nos Estados Unidos e viu que "A pressão intensa gerada pelas demandas da responsabilização leva muitos educadores e diretores a aumentar os escores de maneira que nada têm a ver com a aprendizagem".

Precisa-se começar a investigar como essa política de avaliação está contribuindo para o adoecimento dos docentes. A Tese da Maria Izabel Reis (2014) traz dados importantes para se pensar a saúde dos professores. Sabe-se da dificuldade em se fazer a relação entre trabalho e adoecimento em determinadas profissões, como é o caso do professor. Isso porque os sintomas de adoecimento, ou a própria doença não podem ser atribuídas apenas ao trabalho exercido. Apesar do alto índice de licenças por doenças nas cordas vocais, a voz é também utilizada em outros ambientes que podem, também, ser responsáveis pela sua degradação. Considerando-se esses aspectos das dificuldades no estudo desse tema, a Tese em questão trouxe contribuições importantes que nos permitem ilações com as políticas de avaliação que estão em vigor.

Segundo os dados da pesquisa Trabalho Docente na Educação Básica no Brasil (Maués, 2012), 33\% dos docentes da rede municipal de Belém se afastaram por licença. Desses, 33\% apresentaram patologia das cordas vocais; 33\% dores musculoesqueléticos; $17 \%$, gastrites e 17\%, diabetes. Não necessariamente esse quadro está relacionado à política de avaliação, mas se sabe que a pressão sofrida pelos professores para dar conta dos exames tem sido muito grande. As demandas aumentaram muito, as condições de trabalho (pesquisa Trabalho Docente, 2010) são ruins, o salário não é bom. Há, portanto, um conjunto de variáveis intervenientes que podem contribuir para esse quadro de adoecimento dos professores. 
Os dados da Tese de Reis (2014) também indicam que os professores estão apresentando comportamentos atípicos. Segundo o estudo, $75 \%$ têm chorado mais do que de costume, $58 \%$ têm tido dores de cabeça com frequência, e $42 \%$ têm se sentido triste ultimamente. Ora, essas são informações, que não se pode desprezar, sinalizam para a necessidade de se investigar a fundo a relação desse quadro que está se passando no interior dos sistemas educacionais com essa política de responsabilização.

\section{Chegando ao fim...}

Apesar das críticas que vêm sofrendo, as políticas de avaliação dos resultados por meio de testes externos, padronizados e em larga escala, apesar dos exemplos colocados por pesquisadores de outros países (Ravitch, 2011) e do Brasil (Freitas,2013), essa situação não está ameaçada de terminar. Ao contrário, com a aprovação do Plano Nacional de Educação, ela se solidificou, ganhou estatuto de política de Estado, ampliou-se, incluindo avaliações para crianças de 08 anos de idade.

Parece que há um longo caminho a percorrer para os "reformadores" da educação mudarem de posição, o que é pouco provável em uma sociedade capitalista na qual a acumulação é o objetivo principal e na qual o governo tem tomado medidas que contribuem grandemente para a diluição do espaço entre o público e o privado no que diz respeito ao financiamento da educação.

Há necessidade de se estabelecer um conceito claro sobre qualidade da educação. É preciso entender que, por meio de testes padronizados, o caminho do desenvolvimento econômico e social está prejudicado. Pode-se formar pessoas que saibam o básico exigido pelo mercado, mas não se formam pessoas que desenvolvam o senso crítico, que tenham uma visão de mundo, que compreendam os problemas da sociedade e que se empenhem em resolvê-los. Estamos formando pessoas para responderem a testes padronizados.

Preocupa-nos a memória do país, a história, a geografia, o gosto pela arte, a música, a dança, habilidades que não são pedidas na Prova Brasil, nem na ANA, nem no Saeb, mas que são importantes para a identidade de uma nação, para a conservação de sua historia.

A formação de professores será afetada, aliás, já há uma proposta de um órgão do governo de que não há necessidade de uma formação específica, basta fazer um Prova de conhecimentos e, tendo obtido êxito, poderá haver um curso de algumas horas para a chamada formação pedagógica. De fato, se o papel do professor mudou para "aplicador de testes", não há necessidade de cursos longos, de disciplinas de 
fundamentos da educação, de teorias pedagógicas. Basta "treinamentos" em serviço para atender às metas estipuladas.

Preocupa-nos a participação efetiva nos governos estaduais e municipais, de empresas particulares, inclusive estrangeiras, que estão gerenciando a educação, definindo os conteúdos, elaborando os livros didáticos, treinando os professores e diretores, implantando a gestão empresarial, visando obter a eficácia e a eficiência, sem deixar claro o que entendem por isso. Pior ainda, estão fazendo tudo isso com os recursos públicos, arrecadados por meio dos impostos dos contribuintes.

Finalizo com as considerações de Diane Ravitch (2011, p. 186), que implantou esse sistema de avaliação nos Estados Unidos podendo, pois, fazer uma avaliação dessa política e que diz: "A responsabilização como a conhecemos hoje não está ajudando as nossas escolas. As suas medidas são muito estreitas e imprecisas e suas consequências são severas demais". De forma ainda mais séria, essa autora adverte: "A boa educação não pode ser obtida por uma estratégia de testar as crianças, envergonhar os educadores e fechar as escolas." (2011, p. 132)

\section{Referências}

AFONSO, Almerindo Janela. Avaliação educacional: regulação e emancipação. São Paulo: Cortez, 2005.

ASSUNÇÃO, Mariza Felippe. O Mito da Virtuosidade da Avaliação: Trabalho Docente e Avaliações Externas na Educação Básica. 2013. N. de páginas (192 f) Tese (Doutorado em Educação). Programa de Pós Graduação em Educação, Universidade Federal do Pará, 2013.

BRESSER-PEREIRA, Luiz Carlos. Estado social e reforma gerencial. Revista de Administração de empresa. São Paulo, Fundação Getúlio Vargas, v.50 n.1, pág. 112116, jan-mar. 2010.

BRESSER-PEREIRA, Luiz Carlos. A Reforma do Estado dos anos 90: lógica e mecanismo de controle.Revista Lua Nova. São Paulo, n. 45, pág 49-96, 1998.

BROADFOOT, Patricia. Un nouveau mode de régulation dans un système décentralisé: I'État évaluateur. Revue Française de Pédagogie, France. Institut National de Recherche Pédagogique, n. 130, pág. 43-55, jan- fev-mar. 2000. 
BROOKE. Nigel. O Futuro das Políticas de Responsabilização Educacional no Brasil.

Cadernos de Pesquisa, São Paulo, Fundação Carlos Chagas, v. 36, n. 128, pág 377401, maio-ago. 2006.

BOURDIEU, Pierre. PASSERON, Jean Claude. Les Héritiers. Les étudiants et la culture. Paris: Collection: Le sens comum, 1964

CLARKE, Marguerite. Os pontos mais relevantes para os Sistemas de Avaliação de Estudantes: um documento quadro. Banco Mundial. Washington D.C. 2012. $\mathrm{N}^{\circ}$ de pág 60. Disponível em:<http://siteresources.worldbank.org/INTREAD/ Resources/7526469-1321484244216/2012003155ENGpor_Assembled_Web_ June6.pdf> . Acesson em:13 set 2014

COSTA ALMEIDA et al.O Ideb: Limites e Ilusões de uma Política Educacional. Educação \& SociedadeCampinas, CEDES,v. 34, n. 125, pág. 1153-1174, out.-dez. 2013.

DEMAILLY, Lise. Enjeux et Limites de L'Obligation de Résultats: Quelques Réflexions à Partir de La Politique d'Éducation Prioritaire en France. In LESSARD, Claude. et MEIRIEU, Philippe. L'Obligation de Résultats en Éducation. Québec: PUF Laval, 2004, pág. 105-122.

FREITAS, Helena Costa Lopes. A (nova) política de formação de professores: a prioridade postergada. Educação \& Sociedade, Campinas, CEDES,v. 28, n. 100, pág.1203-1230, out. 2007.

FREITAS, Luiz Carlos. Políticas de Responsabilização: entre a falta de evidência e a ética. Cadernos de Pesquisa, São Paulo, Fundação Carlos Chagas, v.43 n.148 pág. .348-365, jan-abr. 2013.

FREITAS, Luiz Carlos.Os reformadores empresariais da educação: da desmoralização do magistério à destruição do sistema público de educação. Educação \& Sociedade, Campinas, CEDES, v.33, n. 119, pág. 379-409, abr-jun, 2012.

KRAWCZYK, Nora Rut. O PDE: Novo Modo de Regulação Estatal?Cadernos de Pesquisa, São Paulo, Fundação Carlos Chagas,v. 38, n. 135, pág.797-815, set.-dez. 2008.

LESSARD, Claude. Universidade e a formação profissional dos docentes: novos questionamentos. Educação \& Sociedade, Campinas, CEDES. v. 27, n. 94. pág. 201227, jan-abri, 2006. 
LESSARD. Claude. L'Obligation de Résultats em Éducation: de quoi s'agit-il? Le contexte québécois d'une demande sociale, une rhétorique du changement et une extension de la recherche. In LESSARD, Claude. et MEIRIEU, Philippe. L'Obligation de Résultats en Éducation.Québec: PUF Laval, 2004, pág. 23-48.

MAROY, Christian.École, régulation et marché. Une comparaison de six espaces scolaires locaux en Europe. Paris:PUF, 2006

MAROY, Christian. Vers une régulation postbureaucratique des systèmes d'enseignement en Europe. Revue Sociologie et sociétés. Presse Universitaire de Montreal. V, 40m N 1, pág, 31-55, mar-abr-maio, 2008.

MAROY,Christian; DUPRIEZ, Vincent. La régulation dans les systèmes scolaires: proposition théorique et analyse du cadre structurel en Belgique francophone. Revue Française de Pédagogie,France. Institut National de Recherche Pédagogique, n.130, pág. 73-87, 2000.

MAUES, Olgaise Cabral. O Trabalho Docente na Educação Básica: o Pará em questão. Belo Horizonte: Fino Trato Editora, 2012

MEC/INEP. SAEB. Brasília, 2014, Nº́g 01, Disponível em:<http://inep.gov.br/ web/saeb/aneb-e-anresc> Acesso em 08 jan 2015.É preciso rever essa referência RAVELA, Pedro, et al. Las evaluaciones educativasque América Latina necesita. Revista Iberoamericana de Evaluación Educativa, Santiago do Chile,PREAL, pág 51-63, jul, 2008.

PREAL, Lecciones de los sistemas educativos con alto desempeño en PISA: un aporte para las agendas de reforma, MONTEVIDEO, 2011. № pág 04, Disponível em:

http://www.preal.org/Archivos/Preal\%20Publicaciones\%5CPol\%EDticas\%20 y\%20Mejores\%20Pr\%E1cticas\%5CSerie\%20Pol\%EDticas/Polit_39.pdf. Acesso em: 08 jan 2012.

RAVITCH, Diane. Vida e Morte do Grande Sistema Escolar Americano. Como os Testes Padronizados e o Modelo de Mercado Ameaçam a Educação. Porto Alegre: Editora Sulina, 2011.

REIS, Maria Izabel Alves. O Adoecimento dos Trabalhadores Docentes na Rede Municipal de Ensino de Belém. 2014, n. de pág (215) Tese (Doutorado em Educação), Programa de Pós-Graduação em Educação, Universidade Federal do Pará, 2014.

TENRET, Elise. L'École et la Croyance et la Maritocratie. 2008, N de pág (397). Tese (Doctorat en Sociologie) Faculté de Lettres et Sciences Humanis. École doctorale. Université de Bourgogne. 2008. 
UNESCO. Educação de Qualidade Para Todos: um assunto de direitos humanos. Brasília, 2008, $\mathrm{N}^{\circ}$ pág 133, Disponível em:<http://unesdoc.unesco.org/ images/0015/001505/150585por.pdf> . Acesso em : 07 out 2011.

UNESCO. Declaração Mundial sobre Educação para Todos(Conferência de Jomtien - 1990)Plano de Ação para Satisfazer as Necessidades Básicas de Aprendizagem. Brasília, 1999, Nº pág 24, Disponível em:

http://www.unicef.org/brazil/pt/resources_10230.htm. Acesso em: 30 nov 2012.

World Bank. Achieving World Class Education in Brazil: The Next Agenda. Edição Human Development Sector Management Unit Latin America and the Caribbean Regional Office. 2010. № de pág. 137. Disponível em: http://www.anped11.uerj. br/Banco_mundial/achieving_world.pdf > 08 ago. 2012

Recebido em 7 de setembro de 2015

Aprovado em 19 de setembro de 2016

Olgaíses Cabral Maués é Professora Titular; Doutora em Educação. Coordenadora do Grupo de Estudos e Pesquisa sobre Políticas Educacionais, Formação e Trabalho Docente (GESTRADO/PA).Email: olgaises@uol.com.br 